\title{
Left subclavian artery originating from Kommerell diverticulum in the left aortic arch
}

\author{
Masaki Komiyama, MD, and Toshihiro Yasui, MD, Osaka, Japan
}

W

e report an extremely rare case with the left subclavian artery originating from a Kommerell diverticulum in the left aortic arch.

\section{Clinical Summary}

A 26-year-old woman was seen for a 2-year history of occasional left upper extremity numbness when carrying a heavy bag or hanging onto a strap in the train with the left hand. She was neurologically normal and had no dysphagia or dyspnea. Bruit was heard over the left supraclavicular area. There was a difference in blood pressure between the upper extremities. Left blood pressure $(97 / 67 \mathrm{~mm} \mathrm{Hg})$ was about $30 \mathrm{~mm} \mathrm{Hg}$ lower than right blood pressure $(125 / 71 \mathrm{~mm} \mathrm{Hg})$. This difference was not influenced by the positions of the neck and arms.

Computed tomographic angiography (Figure 1) showed the left subclavian artery originating from a Kommerell diverticulum located in the medial aspect of the left aortic arch. The descending aorta was located on the left side. In addition, there was a bulge in the anterior-superior aspect of the left aortic arch, where the normal left subclavian artery usually originates. Axial computed tomographic imaging (Figure 2) showed a medially protruding Kommerell diverticulum.

Transfemoral catheter angiography confirmed these findings. Although the angiography was performed with various positions of the left arm and neck to elicit any functional stenosis of the left subclavian artery, no such stenosis was observed.

\section{Discussion}

Embryologically, a Kommerell diverticulum in the left aortic arch is a remnant of the right dorsal aorta, which usually gives rise to the right aberrant subclavian artery. ${ }^{1}$ In the case presented here, the left subclavian artery originated from the Kommerell diverticulum, and the possible remnant of the normal origin of the left subclavian artery was observed as an aortic bulge. It is presumed that the left subclavian artery, of which the precursor is the left 7th intersegmental artery, migrated to the origin of the left subclavian artery, of which the precursor is the right 7 th intersegmental artery, for an unknown reason during the early embryologic stage. To the best of

From the Department of Neurosurgery, Osaka City General Hospital, Osaka, Japan.

Received for publication July 25, 2006; accepted for publication Aug 8, 2006.

Address for reprints: Masaki Komiyama, MD, Department of Neurosurgery, Osaka City General Hospital, 2-13-22, Miyakojima-Hondori, Miyakojima, Osaka 534-0021 Japan (E-mail: komiyama@japan-mail.com).

J Thorac Cardiovasc Surg 2006;132:1477

$0022-5223 / \$ 32.00$

Copyright (C) 2006 by The American Association for Thoracic Surgery doi:10.1016/j.jtcvs.2006.08.014 our knowledge, this is the first reported case with the left subclavian artery originating from a Kommerell diverticulum in the left aortic arch.

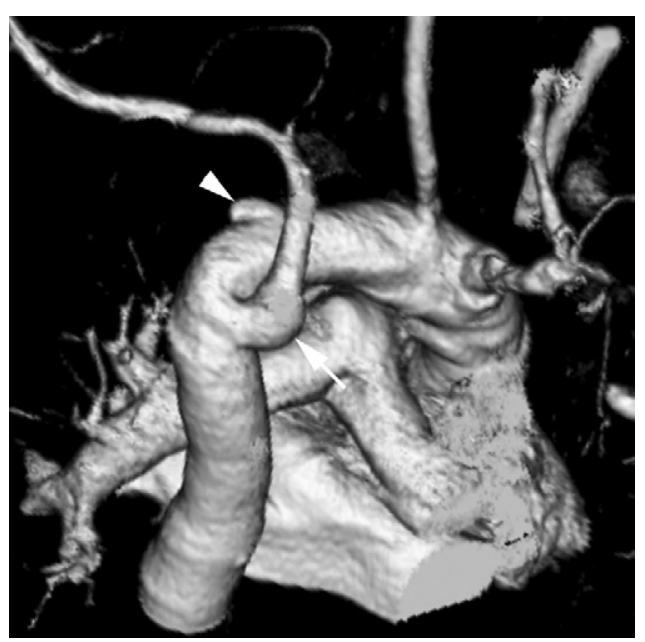

Figure 1. Computed tomographic angiography viewed from back shows Kommerell diverticulum (arrow) and dilatation of presumed remnant of origin of left subclavian artery (arrowhead).

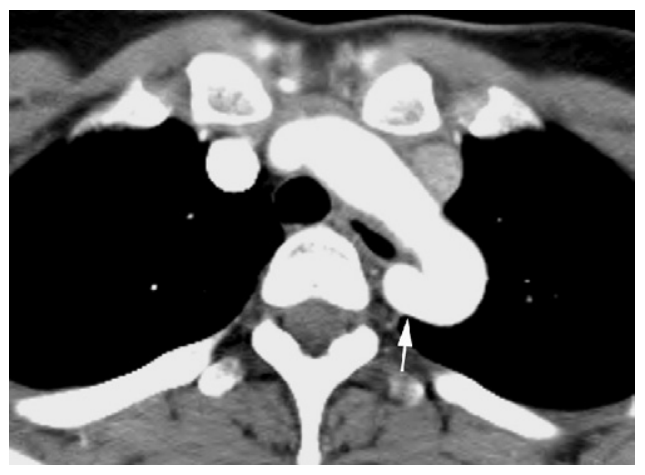

Figure 2. Enhanced computed tomographic scan showing medially protruded Kommerell diverticulum (arrow).

\section{Reference}

1. Kommerell B. Verlagerung des ösophagus durch eine abnorm verlaufende arteria subclavia dextra (arteria lusoria). Fortschr Geb Roentgenstrahlen. 1936;54:590-5. 